\title{
Thoughts on epidemic prevention and control Impact of population migration on epidemic prevention and control in labour-intensive cities and towns during Spring Festival
}

\author{
XueMei Yang, Chongqing University, China \\ Wei Zeng, Chongqing University, Canada \\ Ying Jie Zhao, Chongqing University, China
}

\begin{abstract}
Novel coronavirus pneumonia strikes the city in 2020, making this year special. It also brings us to the attention of the city's public safety and health problem, which directly affects the city's healthy and sustainable development. During the Spring Festival, a large number of migrant workers in labour-intensive cities and towns returned to their places of residence, forming a large-scale population migration across the country, increasing the difficulty of controlling the epidemic. This paper analyzes the labour migration, medical support, government measures and residents of labour-intensive cities and towns, understands the underlying logic of the epidemic situation, puts forward some solutions for urban disaster prevention and control, and increases urban resilience. It mainly includes: 1) building a population mobility information platform, using big data and network to accurately locate, to guide the later epidemic prevention and control and to prevent secondary infection; 2)To solve the problem of insufficient implementation of urban medical supporting facilities and avoid infection on the way to medical treatment, we should set up a temporary medical treatment point according to the "cell neighbourhood" approach in the city; 3)Make good use of online official channels to shorten the time lag between governments in transmitting information and taking measures; 4) It is significant to encourage residents to join in the epidemic prevention and control, to improve the residents' awareness of prevention and control and the ability to distinguish the authenticity of information.
\end{abstract}

\section{Keywords}

Epidemic prevention and control, labour-intensive cities and towns, population migration

\section{Background}

Since the reform and opening up, with the rapid development of China's economy and society, the continuous advancement of urbanization process and the change of population mobility policy, China's large-scale migration, sustained and rapid population migration moving between urban and rural areas, usually across regions. Under the background of the special dual household registration system, there are great differences in trajectory of population flow between China and Western countries. Spatially, the main demographic trend has been to move from the mid-west inland to the eastern and southeast coasts. In the past 40 years of reform and opening up in china, coastal areas have gradually widened the economic development gap with inland areas by virtue of foreign trade, FDI and geographical advantages(Guo and Wang, 2015). As a result, China's labour force has been transferred from rural areas 
to cities, from agriculture to non-agricultural industries, and from the mid-west regions to the East, which has enabled China's economic development to obtain important labour resources(Sun, 2018). In recent years, although the outflow of labour from inland areas is decreasing, coastal areas are still the main force of China's export-oriented economy, attracting most of the labour force in China. According to the research data, the labour outflow provinces mainly include Sichuan, Hubei, Chongqing, Henan, Anhui, Guizhou, Hunan and other central and western regions, with more than 1 million Migration population(Guo and Wang, 2015), which are the main labour supply areas. Therefore, in case of an epidemic in the Spring Festival, the central and western regions are facing a large number of labour returning home, which has brought many challenges to the local epidemic prevention and control work. These include: (1) during the Spring Festival transportation period, migrant workers need to travel between their hometown and work place, which brings a large number of population migration between cities and towns, and improves the probability of virus infection. (2) A large number of migrant workers come from cities or rural areas. Returning home during the Spring Festival is the early stage of the outbreak of the epidemic. Residents will spend a peak period of the epidemic in their hometown. When the symptoms of infection occur, they will gather in one or several hospitals, resulting in the shortage of hospital materials. At the same time, it is easy to cause infection on the way. (3) Government work guidance can not be transmitted from the central government to the local government in time, and the work arrangement obtained by the government managers from the superior has a certain lag in time, which increases the difficulty of government prevention and control and management. (4) Residents generally have low personal cultural literacy and poor ability to distinguish the authenticity of information, and they often become the disseminators of rumours.

\section{Journals reviewed}

Facing COIVD-19 epidemic, in February 10, 2020, Xi Jinping stressed the idea of "stronger confidence, stronger tenacity, more decisive measures, and resolutely win the epidemic prevention and control"(Qing and $\mathrm{Li}, 2020)$. Similar to the novel coronavirus pneumonia outbreak, the impact of large-scale infectious diseases on socio-economic is often more concerned. The impact of this outbreak involves various economic aspects such as national, regional development and people's living standards(Li, 2003). Some scholars think that different from common epidemic diseases, sudden and large-scale epidemic is characterized by sudden outbreak, rapid transmission, relatively concentrated influence area and high degree of social panic(Li-Qun et al., 2009). For novel coronavirus pneumonia outbreak, the migration of infected population is the key to the spread of the epidemic. With the large population migration of Spring Festival, the spread of the disease has spread throughout the country for a short time, which brings many challenges to the epidemic prevention and control. Yang Hualei and others believe that when an epidemic occurs, it is necessary to focus on the prevention and control of the first choice and second choice places of the city where the epidemic broke out. At the same time, we should also prevent and control the main source of population from other cities. In addition to reducing the population migration variables related to the epidemic area, reducing the contact between susceptible and infected people, improving the level of medical care, and inoculating the susceptible population can also inhibit the spread of the epidemic(Yang et al., 2020). Accelerating the construction of big data platform and changing from "closed control" to "accurate intelligent control" is the direction of future development(Zhang et al., 2020). Establish urban intelligent nerve endings to improve the ability of risk information perception and capture(Wang et al., 2020), To reduce the uncertainty caused by population flow and improve the accuracy and efficiency of epidemic prevention and control. Labour intensive cities and towns have strong population mobility during the epidemic period. They are the main export cities of epidemic vectors, and also cities with relatively high proportion of population returning from developed areas. In addition, the medical materials in cities and towns are not complete, so it is difficult to manage 
and prevent and control the cities and towns. Therefore, it is necessary to conduct further research and do a good job in the prevention and control work. Only in this way can we keep pace with the prevention and control work of the central government, make overall planning and do a good job of prevention and control. Therefore, this paper analyzes the labour migration, medical support, government measures, and the role of residents in labour-intensive cities and towns, so as to understand the underlying logic of the epidemic situation, put forward some solutions for urban disaster prevention and control, and increase urban resilience.

\section{Analysis on the characteristics of towns with a large number of labour force under the epidemic situation -- a case study of Yuechi County, Guang'an}

Yuechi County belongs to Guang'an City Sichuan Province, located in the northeast of Sichuan Basin, Qujiang River and Jialing River intersection of the triangle zone. It is $30^{\circ} 15^{\prime}-30^{\circ} 48^{\prime} \mathrm{N}$ and $106^{\circ} 7^{\prime}-106^{\circ} 44^{\prime} \mathrm{E}$. It is adjacent to Guang'an District in the East, Huaying City in the southeast, Hechuan District of Chongqing in the south, Wusheng County in the southwest, Jialing District of Nanchong City in the west, Gaoping District and Pengan County of Nanchong City in the north, with an area of 1479 square kilometers.

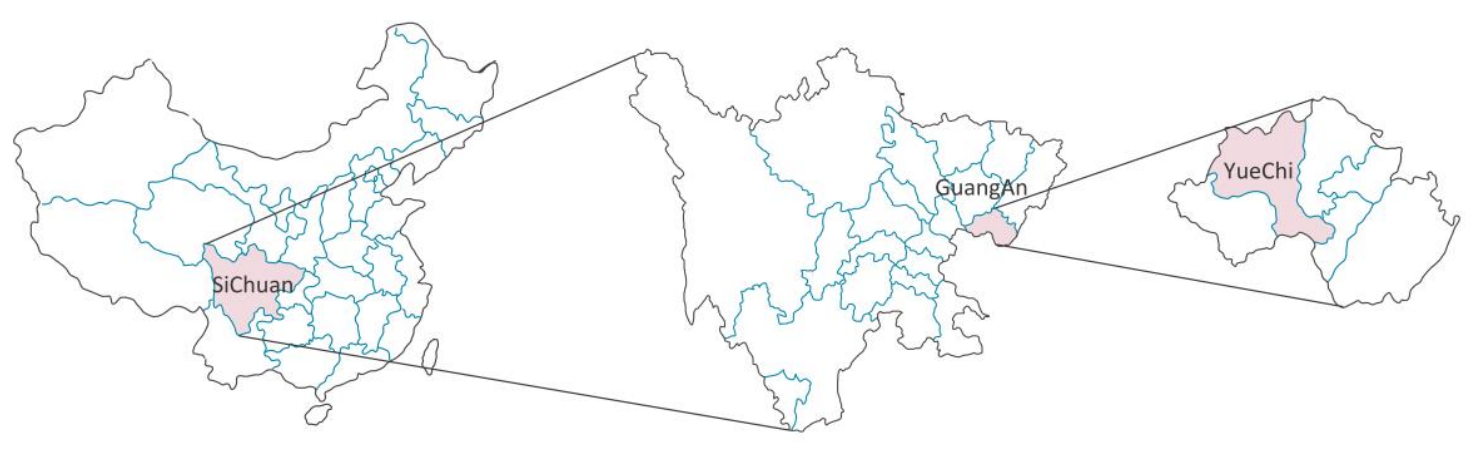

Figure 1. The regional position of Yuechi County in China, Sichuan and Guang'an, Self painted by the author.

According to the "statistical yearbook of Guang'an City in 2019" and the population statistics of Yuechi County People's government, the total household registration population of Yuechi County at the end of the year is 1166600 , the resident population at the end of the year is 782200 , and the resident population is 302100 . The urbanization rate is $17.39 \%$, and the urbanization rate is low. At the same time, the number of jobs that Yuechi County can provide is also small, with urban units accounting for about $5.42 \%$, and non-private sector jobs accounting for about 3.15\%. Therefore, in order to survive, Yuechi County will have a large number of migrant workers, forming about 480000 people during the Spring Festival transportation.

\begin{tabular}{|l|l|l|l|l|l|l|}
\hline $\begin{array}{l}\text { Total } \\
\text { registered } \\
\text { population } \\
\text { at the end } \\
\text { of the year }\end{array}$ & $\begin{array}{l}\text { Total } \\
\text { resident } \\
\text { population } \\
\text { at the end } \\
\text { of the year }\end{array}$ & $\begin{array}{l}\text { Resident } \\
\text { population }\end{array}$ & $\begin{array}{l}\text { Urban } \\
\text { population }\end{array}$ & $\begin{array}{l}\text { Rural } \\
\text { population }\end{array}$ & $\begin{array}{l}\text { Employees of } \\
\text { Urban Units }\end{array}$ & $\begin{array}{l}\text { Average } \\
\text { number of } \\
\text { employees } \\
\text { in non- } \\
\text { private } \\
\text { sector }\end{array}$ \\
\hline 1166600 & 782200 & 302100 & 202900 & 963700 & 63200 & 36700 \\
\hline
\end{tabular}

Table 1. Population analysis, From the "statistical yearbook of Guang'an City in 2019" and the population statistics of Yuechi County People's government. 


\subsection{The number of labor force is huge, and population migration increases the difficulty of epidemic prevention and control}

During the epidemic period, population migration plays a key role in the transmission of the virus, which often leads to the outbreak of acute diseases and the spread of infectious diseases in specific areas(Wang et al., 2020). From Baidu's migration map, the period from the 24th of December to the Chinese new year's day is the peak period for migrant workers to return home, and this year's new year's migration scale index is higher than that of last year. According to the Baidu migration map, during the spread of the epidemic, the population from 30 provinces in China migrated to Guang'an, and the most people moved from Chongqing and Sichuan. Chongqing and Sichuan are close to Hubei, so the probability of epidemic spread is very high. Yuechi is only $26 \mathrm{~km}$ away from Guang'an, and it only takes 40 minutes to drive. Yuechi and Guang'an railway stations are often interconnected, which increases the probability of population mixing with each other, and greatly increases the difficulty of epidemic prevention and control.
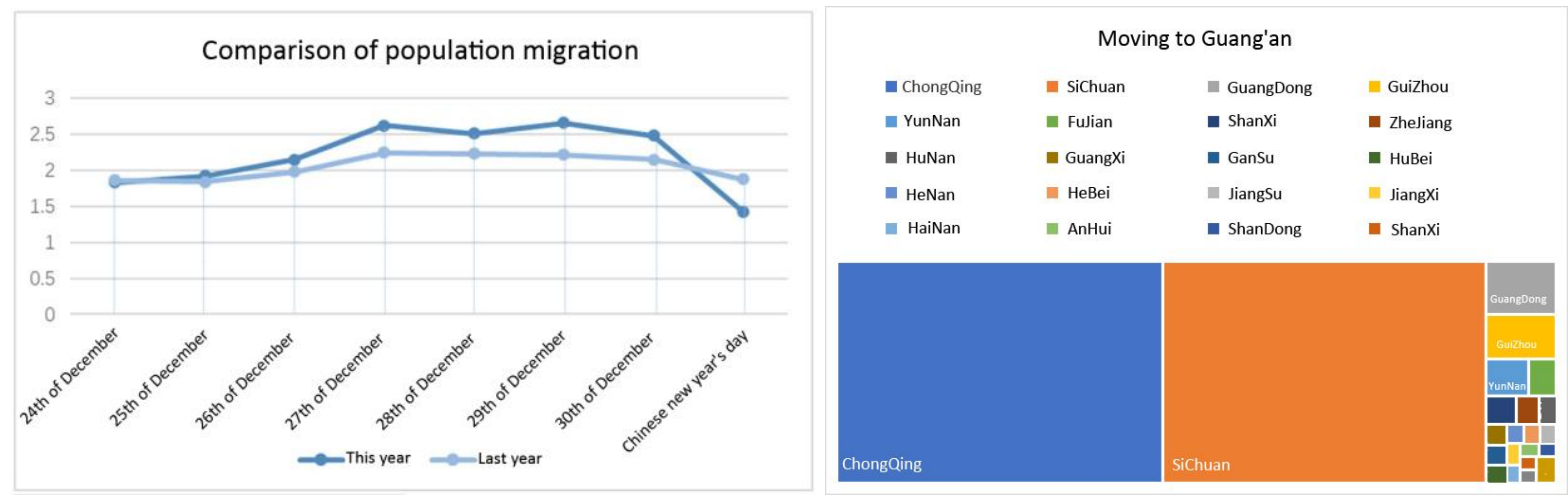

Figure 2. Baidu population migration map, From Baidu map migration data.

\subsection{Hospital facilities are not complete, medical supplies are in short supply}

In the face of public health emergencies, urban hospital public service facilities play a very important role in epidemic prevention and control. In a short period of time, the rapid growth of suspected cases and confirmed cases, hospitals and beds are undoubtedly the most needed hard conditions. There are two major hospitals in Yuechi County, one is Yuechi County People's Hospital, grade III grade B General Hospital, with 800 beds and 1100 open beds; the other is Yuechi County Hospital of traditional Chinese medicine, national class II grade a hospital of traditional Chinese medicine and national Baby Friendly Hospital, with 480 beds. There are 2276 beds in rural hospitals and health centers in Yuechi County. If there is a very serious infection in Yuechi County, the hospital supplies will be very easy to be in a tense state, which is not conducive to the effective control of the epidemic situation.

\subsection{The information of the epidemic situation lags behind, and there is a time lag in the information transmission between the upper and lower levels of the government}

The information conveyed by the government is transmitted according to the administrative level, from the central government to the province, to the prefecture level city, to the county, to the town, and to the township level. As a result, the information gap exists in the information transmission between the upper and lower levels of the government. The lower the administrative level is, the slower the measures for epidemic prevention and control are taken. In January 23, 2020, novel coronavirus infection novel coronavirus infection prevention and control work was held in Wuhan on January 26, 2020 afternoon. The Fourth Symposium was held in Yuechi on the afternoon of January 26, 2020. The meeting conveyed 
the spirit of the conference on prevention and control of the government at the higher level, and reported the recent situation of pneumonia prevention and control in the new coronavirus infection in Yuechi County, and arranged the work for the next work. Yuechi County held a meeting three days after the closure of Wuhan city. During this period, the population who came back before the closure of Wuhan city is likely to flow into the county, which increases the difficulty in mastering accurate information of the epidemic situation, population management, and epidemic prevention and control.

\subsection{Residents' behaviour consciousness is weak and self-restraint ability is poor}

In the early stage of the epidemic, the residents paid more attention to the folk customs such as family reunion and visiting relatives and friends, but paid less attention to the information related to the epidemic situation. Some residents had a relatively calm attitude towards the epidemic situation. Through the "new questionnaire" small program to carry out the questionnaire survey, among 109 questionnaires, $22.94 \%$ of the people think that they will not be infected, and $13.76 \%$ of them think that everything will be as it is and let it be.

Residents become the disseminators of rumours. As of June 2019, the number of Internet users in China has reached 854 million, and the Internet penetration rate has reached $61.2 \%(\mathrm{Wu}, 2020)$. Residents can obtain information from all directions through the Internet, but their ability to distinguish the authenticity of information is weak, so they are easy to become the disseminators of rumours. According to the survey, $36.7 \%$ of the respondents would forward the uncertain information to their relatives and friends. The reason may be that the students and those with bachelor's degree or above have a good understanding of covid-19(Hu et al., 2020), There are more channels to obtain information(Luo et al., 2020). But in the floating population, there are a large number of residents are migrant workers born in the 1970s and 1980s, with low education level and poor self-discrimination ability, which has become the disseminator of rumours and the booster of social panic.

The self-restraint ability of residents is weak. Once the epidemic situation improves, the phenomenon of residents gathering and shopping will repeat. In addition, most of the residents in labour-intensive cities and towns work in other places, and their work and income are not guaranteed during the epidemic period. If they have the opportunity to work outside, they will choose to go out to work at the risk of being infected.

\section{Proposal}

\subsection{Build big data of population flow to support the follow-up prevention and control work}

Compared with the SARS period in 2003, the most significant feature at this stage is the rapid development of information technology(Li and Zhu, 2020). Spatiotemporal big data is increasingly becoming an important driving force to promote the modernization of social governance system and governance capacity(Ji and Zhao, 2014; Wang et al., 2017). The results show that using continuous and systematic data to explain the unpredictable behaviour changes can effectively improve the management state of chaos and disorder(M et al., 2018; Zhou et al., 2019).

It is the key for the government to grasp comprehensive and accurate information in time(Zhou and Chen). Big data can monitor the changes of population flow in real time, early warning and assess potential risks. When urban managers make decisions, they can provide strong data support. For the cities and towns with large inflow population, it is necessary to know the relevant information of the inflow population accurately at the first time, including the physical condition, where it comes from and 
so on. We can collect personnel information through the channels of railway stations, passenger stations and high-speed intersections, and supplement the information of foreign personnel registered in communities and villages to build a unified big data platform. Select the people who come back from Wuhan and have contact history with Wuhan, and then share the data with the government and various institutions and platforms. Meanwhile, closely observe the inflow of population from Wuhan and the population with contact history in Wuhan. Once symptoms are found, relevant measures such as isolation shall be taken in time. Suspected cases and confirmed cases shall be fed back to the information platform to improve the floating personnel information database.

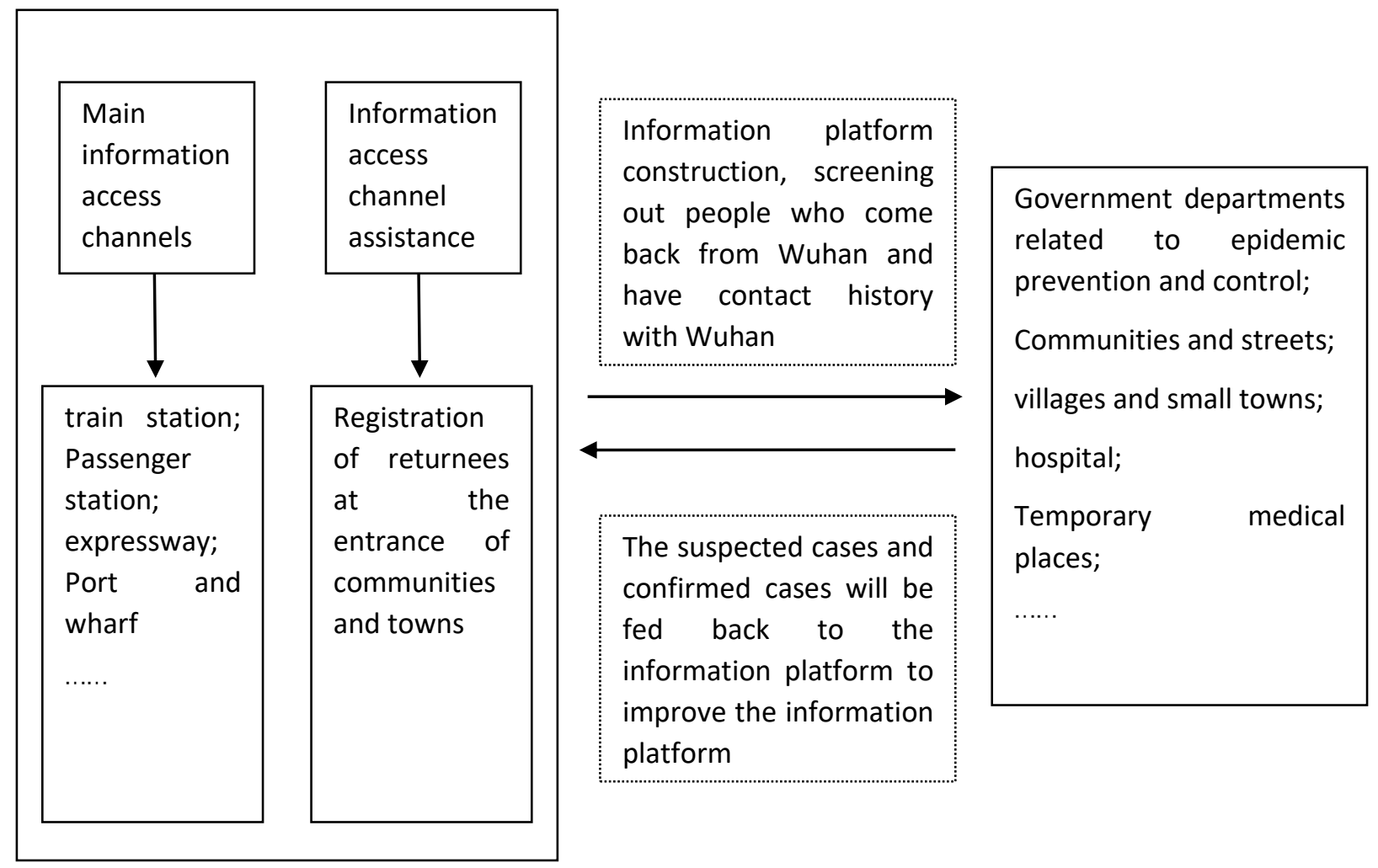

Figure 3. Construction of information platform for population flow data, Self-painted by the author.

\subsection{Setting up temporary medical treatment centers for urban "cell neighbourhood units"}

With the outbreak of the epidemic in Wuhan, Huoshenshan hospital and Leishenshan hospital were built as infectious disease hospitals to treat patients, so as to alleviate the problem of beds and patients' medical difficulties. In the face of sudden infectious diseases, treatment requires the city to respond to emergencies in time. In labour-intensive cities and towns, the free land in the suburbs and towns can be used as the "blank" space, and the flexible space is large.

During the epidemic period, temporary medical treatment centers should be set up in accordance with the biological "cell neighbourhood" organization to relieve the pressure of insufficient medical facilities. The whole city was set up as a temporary medical treatment center according to the 10 minutes, 15 minute and 20 minutes life circle. In addition, temporary medical treatment centers are also set up in township health institutions. When the residents have fever and other symptoms, they can go to the temporary medical treatment point directly to avoid wasting medical materials and wasting time in the hospital queue. At the same time, it also reduces the probability of infection. If the infection is very serious, the temporary medical treatment point should do a good job of isolation, do a good job of preliminary treatment, and contact the hospital, escort the patient to the hospital for comprehensive treatment. 
Each neighbourhood unit should build an intercommunication information platform, on which the medical materials of each unit can be clearly displayed. Once a certain unit of medical supplies is insufficient, other units should supplement in time. Through this platform, we can understand the virus situation in a certain region. Once the virus spread in a concentrated area, we should immediately take the way of closing the unit to block the virus diffusion, so as to increase the resilience of the city in the face of disaster.

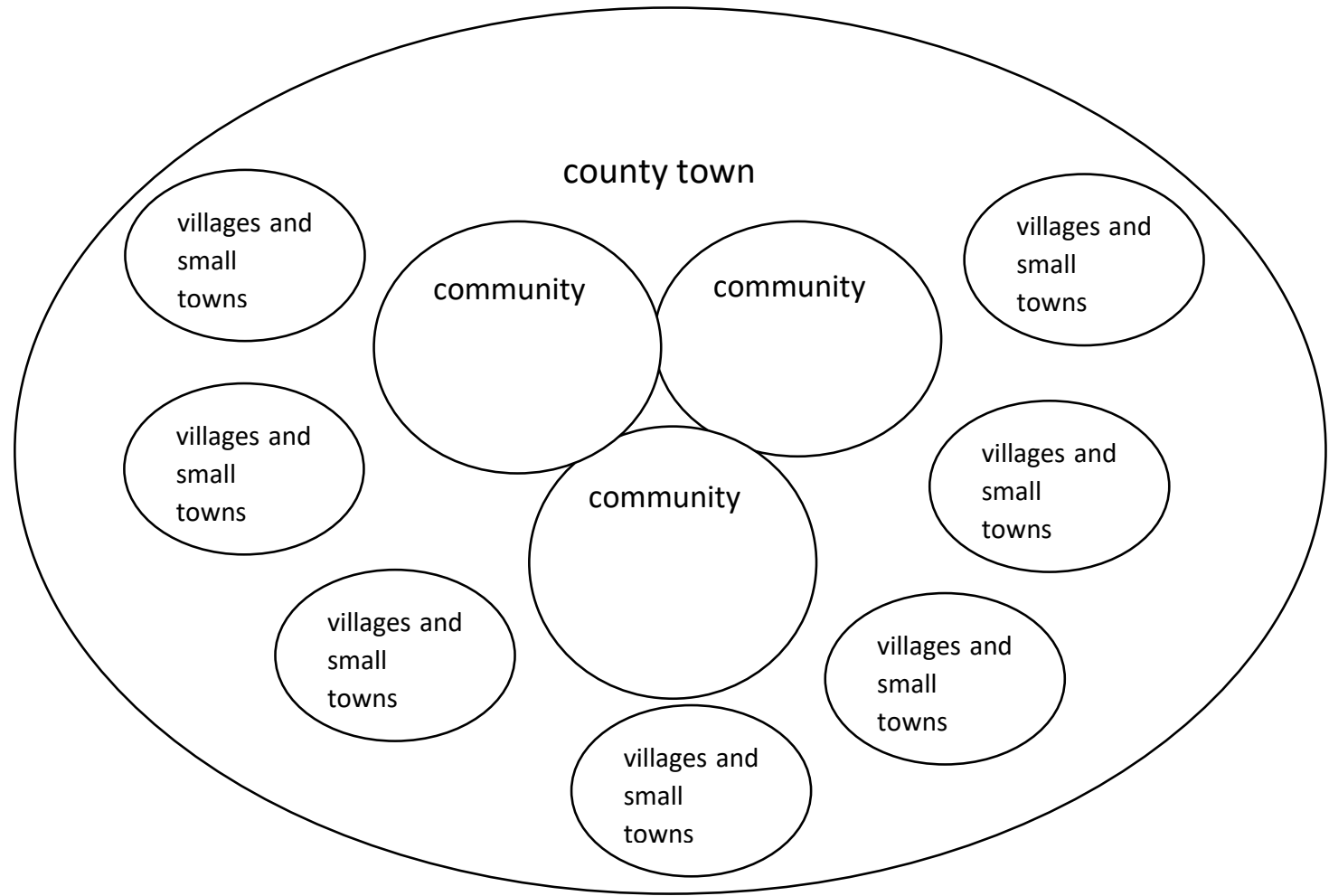

Figure 4. The model of temporary medical treatment point in urban "cell neighborhood unit", Self-painted by the author .

\subsection{Build emergency system and strengthen online management channel}

Faced with the uncertain and uncertain trend of the epidemic situation, local public managers and decision makers bear great pressure from superior departments and the public. However, the response of local governments is relatively slow and in a state of confusion, which requires local governments to master the methods of preventing and controlling the epidemic situation(Li, 2020).

To construct the government emergency management system. In the face of public health emergencies, the government can timely through the emergency management system to achieve pre prevention, response and post repair, improve the efficiency of work. The emergency system includes the establishment of an epidemic prevention and control team, assigning tasks to specific people and incorporating them into the final performance appraisal; Based on the big data of population flow, make accurate judgments and choices; The official media should release the real information of the epidemic situation at the first time, so that the residents can understand the situation of the epidemic situation, and stimulate the residents to jointly attack the epidemic war.

Refute rumours through network channels in time. At present, the number of Internet users is increasing, and there are also many social networking platforms. When people can't go out, the network platform becomes a medium for people to connect with each other and see the world. However, the social network platform has many shortcomings, and sometimes it has become a medium for people to spread rumours and create social panic. The wrong speech on the network platform can be spread in a short 
time, which will lead to social disorder and cause unnecessary social panic. So, the government should promptly restore the facts by official WeChat, $Q Q$, micro-blog, Tik-Tok and other online ways to rumour, and at the same time, publicize the epidemic prevention and control knowledge on the Internet platform to appease the residents' mood.

\subsection{Let residents become the assistant of epidemic prevention and control}

The interests of residents will be more or less affected in public health emergencies. Residents should cooperate with the government and social public organizations to actively perform the prevention and control obligations, so as to achieve overall prevention and control benefits(Gao, 2010).

In this epidemic war, the individual behaviour of residents plays a very important role. Residents can become a powerful assistant in epidemic prevention and control. If every resident does a good job in protection, improves the awareness of prevention and control and the ability to distinguish the authenticity of information, and obeys the management, the epidemic situation will be slowly controlled.

\section{Summary}

In China, the new urbanization path which takes the agricultural transfer population citizen as the important content, the labour population migration is still the remarkable phenomenon of population flow. China's labour migration includes a large number of inter provincial migration population, which has the characteristics of long-distance and large-scale population flow. The population flow in labourintensive cities and towns during the Spring Festival has brought huge potential risks to the cities and towns. We need to be prepared for accurate prevention in time, Through case study, this paper reviews the response of traditional rural labour migration towns to major public emergencies in the new epidemic, and puts forward some suggestions, such as building a population mobility information platform, setting up temporary medical treatment points, and using official network channels for online management. These opinions are of positive significance for the current and future epidemic prevention and control, and the study of labour force population is of great significance to regional social and economic development.

\section{References}

D, B. E. \& F, W. P. (2008), "Role of immigrants and migrants in emerging infectious diseases.", The Medical clinics of North America, Vol. 92 No. 6, pp.

Gao, W. M. (2010), "Citizen's obligation in prevention and control of sudden infectious diseases", Studies in Law and Business, Vol. 27 No. 01, pp. 20-29.

Guo, D. J. \& Wang, X. Q. (2015), "The impact of economic opening on regional labor mobility in China", Northwest Population Journal, Vol. 36 No. 02, pp. 1-5+12.

Hu, Y. K., Zhang, G. Q., Li, Z. H., Yang, J. N., Mo, L. J., Zhang, X. R., Xiong, L. L., Wu, W. L., Mao, C. \& Yang, X. F. (2020), "Survey on knowledge, attitude and behavior of covid-19 among residents in severe epidemic areas", Journal of Southern Medical University, Vol. 40 No. 05, pp. 733-740.

Ji, G. L. \& Zhao, B. (2014), "overview of spatiotemporal data mining for big data", Journal of Nanjing Normal University(Natural Science Edition), Vol. 37 No. 01, pp. 1-7.

Li, X. Y. \& Zhu, J. H. (2020), "Interpretation and response novel coronavirus pneumonia epidemic situation from the perspective of tough City", Planners, Vol. 36 No. 06, pp. 65-68.

$\mathrm{Li}$, Y. (2020), "Improving the governance ability of local leading cadres in the fight against major epidemics", Leadership Science, No. 10, pp. 4-7.

Li, Z. Q. (2003), "Short term and long term analysis of SARS affecting national economy", Economic Science, No. 03, pp. 25-31.

Li-Qun, F., de Vlas Sake J, Dan, F., Song, L., You-Fu, X., Jie-Ping, Z., Hendrik, R. J. \& Wu-Chun, C. (2009), 
"Geographical spread of SARS in mainland China.", Tropical medicine \& international health : TM \& IH, Vol. 14 Suppl 1.

Luo, L., Zeng, X. J., Liao, X. \& Yang, Y. Q. (2020), "COIVD-19 epidemic: public awareness of disease, coping style and exercise behavior", Chinese Journal of Public Health, Vol. 36 No. 02, pp. 156-159.

M, M. A. K., Hossain, K. M., Rezina, P., Sharmin, S., Nawsher, A. A., Arifa, A., Mahmudur, R. \& Tahmina, S. (2018), "Event based surveillance of Middle East Respiratory Syndrome Coronavirus (MERS- CoV) in Bangladesh among pilgrims and travelers from the Middle East: An update for the period 20132016.", PloS one, Vol. 13 No. 1, pp.

Qing, Y. \& Li, G. (2020), "COIVD-19 epidemic: overview of the challenges and impacts on China's economy", Regional Economic Review, No. 03, pp. 146-156.

Sun, Z. Y. (2018), "Labor mobility and employment structural contradiction", Study \& Exploration, No. 12, pp. 50-56.

Wang, F., An, L., Huang, R. H., Huang, Y. T., Wang, X. W., Zhang, G. Y. \& Liu, L. J. (2020), "Scientific response and thinking in public health emergencies", Document,Information \& Knowledge, No. 02, pp. 4-14.

Wang, J. Y., Wu, F., Guo, J. Z., Cheng, Y. \& Chen, K. (2017), "Challenges and opportunities of spatiotemporal big data", Science of Surveying and Mapping, Vol. 42 No. 07, pp. 1-7.

Wu, C. Y. (2020), "Government strategy for epidemic prevention and control: judgment and decisionmaking, prevention and control plan, information disclosure", Leadership Science, No. 08, pp. 14-15.

Yang, H. L., Wu, Y. Y. \& Lin, X. Y. (2020), "Prevention and control of COIVD-19 epidemic, population migration and epidemic spread", Chinese Journal of Management Science, Vol. 28 No. 03, pp. 1-10.

Zhang, H., Shen, H. L. \& Xia, L. (2020), "COIVD-19 epidemic prevention and control capacity construction based on big data perspective", Acta Mathematicae Applicatae Sinica Series, Vol. 43 No. 02, pp. 468481.

Zhou, H. Z., Lei, Q. M. \& Zhu, Y. F. (2019), "Practice of quality education management in Medical College Based on Chaos Theory", Education Forum, No. 33, pp. 14-15.

Zhou, X. M. \& Chen, L. "Improving the government's ability of public health emergency management driven by big data-Population information management of local government during epidemic period", Price:Theory\&Practice, 1-4. 